\title{
AEROSOL VARIABILITY OBSERVED WITH RPAS
}

\author{
B. Altstädter ${ }^{\text {a, }}$, A. Lampert ${ }^{\text {a }}$, A. Scholtz ${ }^{\text {a }}$, J. Bange ${ }^{\text {b }}$, A. Platis ${ }^{\text {b }}$, M. Hermann ${ }^{c}$, B. Wehner ${ }^{c}$ \\ ${ }^{a}$ Institute of Aerospace Systems, TU Braunschweig, Hermann-Blenk-Str. 23, 38108 Braunschweig, Germany - \\ Astrid.Lampert@tu-braunschweig.de, a.scholtz@tu-braunschweig.de \\ b Universität Tübingen, Center for Applied Geophysics, Hölderlinstr. 12, 72076 Tübingen, Germany - jens.bange@ uni- \\ tuebingen.de, andreas.platis@uni-tuebingen.de \\ ${ }^{\mathrm{c}}$ Leibniz Institute for Tropospheric Research, Permoserstr. 15, 04318 Leipzig, Germany - \\ markus.hermann@tropos.de, birgit.wehner@tropos.de
}

KEY WORDS: RPAS, aerosol, turbulence, atmospheric boundary layer, aerosol variability

\begin{abstract}
:
To observe the origin, vertical and horizontal distribution and variability of aerosol particles, and especially ultrafine particles recently formed, we plan to employ the remotely piloted aircraft system (RPAS) Carolo-P360 "ALADINA" of TU Braunschweig. The goal of the presented project is to investigate the vertical and horizontal distribution, transport and small-scale variability of aerosol particles in the atmospheric boundary layer using RPAS.

Two additional RPAS of type MASC of Tübingen University equipped with turbulence instrumentation add the opportunity to study the interaction of the aerosol concentration with turbulent transport and exchange processes of the surface and the atmosphere. The combination of different flight patterns of the three RPAS allows new insights in atmospheric boundary layer processes.

Currently, the different aerosol sensors are miniaturized at the Leibniz Institute for Tropospheric Research, Leipzig and together with the TU Braunschweig adapted to fit into the RPAS. Moreover, an additional meteorological payload for measuring temperature, humidity and turbulence properties is constructed by Tübingen University. Two condensation particle counters determine the total aerosol number with a different lower detection threshold in order to investigate the horizontal and vertical aerosol variability and new particle formation (aerosol particles of some nm diameter). Further the aerosol size distribution in the range from about 0.300 to $\sim 5 \mu \mathrm{m}$ is given by an optical particle counter.
\end{abstract}

\section{INTRODUCTION}

\subsection{Motivation}

The formation of a large number of new nucleation mode particles (size range from $\sim 3$ to $15 \mathrm{~nm}$ diameter) in the atmospheric boundary layer (ABL) has been observed worldwide at various sites and constitutes a significant source of the atmospheric aerosol. Different nucleation processes lead to the formation and, if sufficient condensable gases are available, subsequent growth of particles to a detectable size above $3 \mathrm{~nm}$ and to larger sizes within a few hours. Then they act as cloud condensation nuclei and scatter solar radiation, which influences the regional and global climate. Thus, being able to understand and predict new particle formation is a key issue in understanding and quantifying the aerosol effects on climate (Spracklen et al., 2008). In the atmospheric boundary layer, particle bursts have been reported in the entrainment zone, the residual layer, and throughout the convectively mixed-layer.

The RPAS has the potential to close the gap of atmospheric aerosol measurements between long-term ground-based observations and long-range aircraft measurements. Complementary to these measurements, RPAS observations allow for investigating the small-scale and short-term aerosol variability in vertical and horizontal direction at low cost and with minimal logistical requirements.

The challenge is to modify small handheld instruments to meet the mass, power and size requirements of the RPAS, to obtain acceptable temporal resolution, and to calibrate the miniaturized systems.

\subsection{Aims}

Overall goal of the project is to investigate the vertical and horizontal distribution, transport and small-scale variability of aerosol particles in the ABL using highly flexible RPAS. The new RPAS ALADINA (Application of Light-weight Aircraft for Detecting In situ Aerosol, Fig. 1) is currently being modified at TU Braunschweig and equipped with aerosol instrumentation.

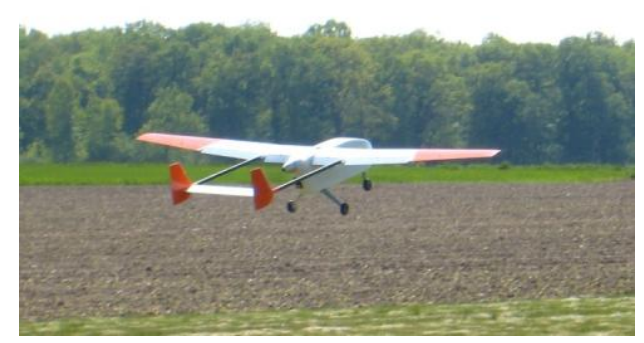

Figure 1. ALADINA during take-off

Two additional RPAS of type MASC (Multi-purpose Automatic Sensor Carrier) equipped with turbulence instrumentation by University Tübingen add the opportunity to study the interaction of the aerosol concentration with turbulent 
transport and exchange processes of the surface and the atmosphere.

The three main aims of the project are:
a) The development, characterisation and integration of a miniaturized aerosol payload
b)
The characterisation and calibration of the aerosol UAV system in the field
c)
The investigation of $\mathrm{ABL}$ aerosol and its variability

\subsection{Aerosol variability and particle bursts}

The earth's surface can act either as a source or sink for aerosol particles. Aerosol formation, uptake, mixing, growth and gravitational settling proceed throughout the ABL. The vertical aerosol concentration is connected to the thermodynamic structure. It is well mixed in a turbulent ABL and forms layers of different concentration and properties if the atmosphere is stably stratified. Aerosol particles modify the ABL in many ways: Especially particles in the accumulation mode (about $\sim 100$ to $1000 \mathrm{~nm}$ ) interact with solar and terrestrial radiation and have a direct impact on the radiation budget (IPCC, 2007). Depending on the aerosol properties and the surroundings, the effect can be an additional positive (warming) or negative (cooling) surface forcing (Lohmann and Feichter, 2005), influencing the driving force of convection and the development of the ABL structure (e.g. Yu et al., 2002). Aerosol particles also serve as cloud condensation nuclei (CCN), enable cloud formation in a saturated environment and modify cloud properties (indirect aerosol effect, Kerminen et al., 2005).

As the vertical distribution of aerosol in the ABL is strongly correlated with turbulent activity (Boy et al., 2003), simultaneous profile measurements of aerosol concentrations and turbulent parameters serve to identify source altitudes and transport (Buzorius et al., 2001). In a stable stratified boundary layer, complex processes involving aerosol take place at different altitudes, which cannot be monitored by ground-based observation sites (Corrigan et al., 2008). During subsequent vertical and horizontal mixing, the particles are redistributed and reach different locations.

The formation of a large number of new nucleation mode particles (size range from $\sim 3$ to $15 \mathrm{~nm}$ diameter) in the ABL has been observed worldwide at various rural, marine and urban observation sites and constitutes a significant source of the atmospheric aerosol (Kulmala et al., 2004). Different nucleation processes lead to the formation and, if sufficient condensable gases are available, subsequent growth of particles to a detectable size above $3 \mathrm{~nm}$ and further to the Aitken mode size $(\sim 15$ to $100 \mathrm{~nm})$ within a few hours. Then they act as CCN and scatter solar radiation, influencing the regional and global climate (Spracklen et al., 2008). Wiedensohler et al. (2009) showed that new particle formation (NPF) may enhance the available $\mathrm{CCN}$ by an order of magnitude. Being able to understand and predict is a key issue in quantifying the direct and indirect aerosol effects on climate. Above a certain particle diameter volatile material dominates the particle growth (Wehner et al., 2007). Ground-based observations of particle bursts were connected to intense solar radiation, high vertical wind variance (indicating a strong turbulent mixing), downward particle flux, low water vapour concentration and enhanced ozone concentration (Boy et al., 2003). NPF was observed with increased turbulence within the RL (Wehner et al., 2010), while these particles were mixed downwards and detected at ground stations. Ground-based observations revealed a mesoscale horizontal extent of NPF over hundreds of km (Wehner et al., 2007). Airborne measurements investigated the large scale variability of the particle concentrations along air mass trajectories (O'Dowd et al., 2009). Detailed measurements of the vertical and horizontal variability are recommended for the implementation of NPF in models (Boy et al., 2006).

\section{RPAS FOR AEROSOL OBSERVATION}

\subsection{Carrier platform}

ALADINA provides a unique and flexible tool for characterizing the vertical and horizontal variability of the boundary layer aerosol. The Carolo-P360 with a wingspan of $3.6 \mathrm{~m}$ was designed at TU Braunschweig (Scholtz, 2009) to carry up to $2.5 \mathrm{~kg}$ of payload in the front compartment (Fig. 2). With electrical propulsion, it has an endurance of about 40 minutes. The cruising speed is $25 \mathrm{~m} / \mathrm{s}$. It is equipped with an emergency landing system (parachute). An electric motor is used as it reduces vibrations, and the centre of gravity is constant during flight. After changing the battery pack and saving the data, the system is ready for flight again in less than $20 \mathrm{~min}$. With four sets of battery packs and parallel charging of batteries it is possible to cover the daily evolution of the ABL. The system starts on an undercarriage released after take-off without the need of special infrastructure and lands directly on the fuselage on soft and flat terrain (e.g. grass, snow field) with a dimension of $60 \mathrm{~m} \times 25 \mathrm{~m}$. In summer 2011, the new UAV was subject to extensive flight tests demonstrating convincing flight properties and good reliability. The flight altitudes of the new platform cover the range of the $\mathrm{ABL}$ (up to $3 \mathrm{~km}$ ). A typical flight pattern for aerosol detection consists of a vertical profile up to the top of the ABL to identify altitudes of interest. Then longer horizontal flight legs of several $\mathrm{km}$ are performed to explore the spatial variability of the aerosol. The same board computer, autopilot system, and meteorological and navigation sensors are implemented as for the MASC systems.

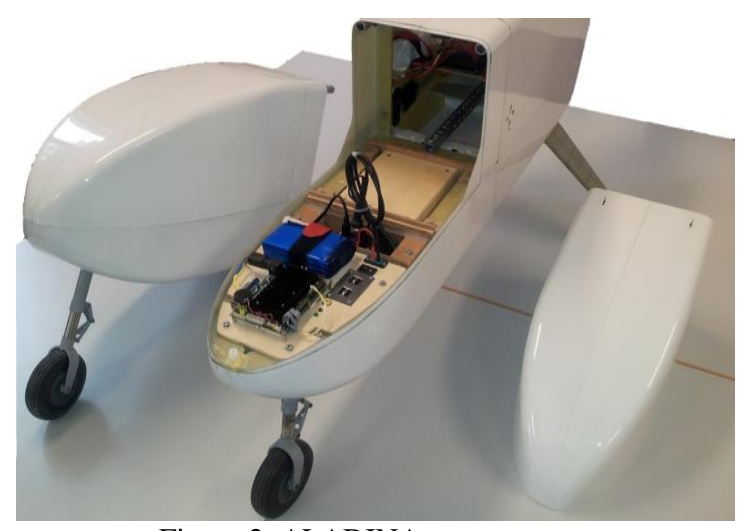

Figure 2. ALADINA sensor compartment

\subsection{Instrumentation}

The aerosol instrumentation consists of an optical particle counter (OPC) and two condensation particle counters (CPC). Commercially available instruments are miniaturized at the Leibniz Institute for Tropospheric Research (TROPOS), Leipzig. The OPC GT-526 (Met-One) provides 6 channels in the particle size range from $\sim 0.3$ to $\sim 5.0 \mu \mathrm{m}$. More channels are not useful, because on the one hand the miniaturized OPC shall be fast, i.e., have a relatively high time resolution $(\sim 0.5 \mathrm{~Hz})$, which is needed to resolve the small scale aerosol features in the ABL. On the other hand statistics (how many particles are counted in one channel) limit both the time resolution and the 
number of channels. The CPCs 3007 (TSI) are handheld instruments. As the CPCs can only be operated in a narrow temperature window $\left(10-35^{\circ} \mathrm{C}\right)$ the counters must be well insulated. The temperature difference between the saturator and condenser of the CPCs is adjusted to achieve two different lower threshold diameters (e.g. 6 and $12 \mathrm{~nm}$ ). This operation mode allows deriving the concentration of freshly formed nucleation mode particles. The response time of the original instruments is improved, as the default value of $\sim 9 \mathrm{~s}$ is too slow for resolving the small scale aerosol features in the ABL. Finally, the two CPCs are calibrated using the TROPOS calibration facilities.

The whole aerosol payload can be operated as a stand-alone system. It has its own power supply batteries and can be operated independently from the RPAS. The payload shall be finally tested under realistic ambient conditions, i.e. temperatures down to $0^{\circ} \mathrm{C}$ and operating pressures down to 800 $\mathrm{hPa}$.

\subsection{Current status}

A prototype of ALADINA has been extensively tested. The reliability of the emergency parachute and the start with undercarriage released after take-off has been demonstrated. The aircraft that will be used for the aerosol measurements is currently being modified for housing the aerosol instruments. Interfaces between the aerosol instruments and the central data acquisition are exchanged. The aerosol instruments will be miniaturized and are tested and calibrated. The turbulence payload and the central data acquisition are ready for implementation. The next step will be to assemble the miniaturized aerosol instruments as well as the data acquisition and turbulence payload in the ALADINA sensor compartment and fuselage and to perform necessary modifications to improve the weight and balance.

\subsection{Planned campaigns}

Field experiments of the aerosol sensor carrier ALADINA in combination with two meteorologically equipped MASC are planned to study the influence of turbulence on the particle distribution. After the implementation and test phase, a first scientific application is planned for autumn 2013 at the aerosol monitoring station Melpitz near Leipzig, Germany. The aim is to identify the location and altitude of the so-called particle bursts, i.e. events of new particle formation, in the atmospheric boundary layer. The events will be analysed in dependence of turbulence properties and in the context of the synoptic situation. For 2014, a direct intercomparison of vertical aerosol profiles with other airborne platforms is planned.

\section{OUTLOOK}

To fill the gap between ground-based measurements and costintensive long-range airborne observations, the aerosol sensor carrier ALADINA provides a flexible tool for observing horizontal and vertical aerosol variability. The aim is to contribute information about particle formation events and to better understand mechanisms by airborne observations on small scales. ALADINA can further be used as a path finder for providing vertical aerosol profiles and help to decide on the operation of other airborne sensors with manned aircraft. In the future, validation of aerosol properties observed with remote sensing instruments (multi-wavelength lidar) is planned.

The combination of three RPAS operating simultaneously provides information on the correlation of various atmospheric parameters, like aerosol homogeneity, turbulence and atmospheric stratification.

\section{REFERENCES}

Boy, M., Rannik, Ü., Lehtinen, K.E.J., Tarvainen, V., Hakola, H., and Kulmala, M., 2003. Nucleation events in the continental boundary layer: Long-term statistical analyses of aerosol relevant characteristics, J. Geophys. Res., 108, D21, 4667, doi:10.1029/2003JD003838.

Boy, M., Hellmuth, O., Korhonen, H., Nilsson, E.D., ReVelle, D., Turnipseed, A., Arnold, F., and Kulmala, M., 2006. MALTE - model to predict new aerosol formation in the lower troposphere, Atmos. Chem. Phys., 6, 4499-4517.

Buzorius, G., Rannik, Ü., Nilsson, D., and Kulmala, M., 2001. Vertical fluxes and micrometeorology during aerosol particle formation events, Tellus, 53B, 394-405.

Corrigan, C.E., Roberts, G.C., Ramana, M.V., Kim, D., Ramanathan, V., 2008. Capturing vertical profiles of aerosols and black carbon over the Indian Ocean using autonomous unmanned aerial vehicles, Atmos. Chem. Phys., 8, 737-747.

IPCC: Climate Change 2007, 2007. The Physical Science Basis. Contribution of Working Group I to the Fourth Assessment Report of the Intergovernmental Panel on Climate Change, Solomon, S., Qin, D., Manning, M., Chen, Z., Marquis, Z.M., Averyt, K.B., Tignor M., and Miller, H.L. (eds.), Cambridge University Press, 996 pp.

Kerminen, V.-M., Lihavainen, H., Komppula, M., Viisanen, Y., and Kulmala, M.,2005. Direct observational evidence linking atmospheric aerosol formation and cloud droplet activation, Geophys. Res. Lett., 32, L14803, doi:10.1029/2005GL023130.

Kulmala, M., Vehkamäki, H., Petäjä, T., Dal Maso, M., Lauri, A., Kerminen, V.-M., Birmili, W., McMurry, P.H., 2004. Formation and growth rates of ultrafine atmospheric particles: a review of observations, Aerosol Scie., 35, 143-176.

Lohmann, U., and Feichter, J., 2005. Global indirect aerosol effects: a review, Atmos. Chem. Phys., 5, 715-737.

O'Dowd, C.D., Yoon, Y.J., Junkermann, W., Aalto, P., Kulmala, M., Lihavainen, H., and Viisanen, Y., 2009. Airborne measurements of nucleation mode prticles II: boreal forest nucleation events, Atmos. Chem. Phys., 9, 937-944.

Scholtz, A., 2009. Design and Construction of a UAVPrototype with Emergency Landing System, diploma thesis F 0828 D, Technical University Braunschweig.

Spracklen, D. V., Carslaw, K. S., Kulmala, M., Kerminen, V.M., sihto, S.-L., Riipinen, I., Merikanto, J., Mann, G. W., Chipperfield, M. P., Wiedensohler, A., Birmili, W., and Lihavainen, H., 2008. Contribution of particle formation to global cloud condensation nuclei concentration, J. Geophys. Res,. 35, L06808, doi:10.1029/2007GL033038.

Wehner, B., Siebert, H., Stratmann, F., Tuch, T., Wiedensohler, A., Petäjä, T., Dal Maso, M., and Kulmala, M., 2007. Horizontal homogeneity and vertical extent of new particle formation events, Tellus, 59B, 362-371. 
Wehner, B., Siebert, H., Ansmann, A., Ditas, F., Seifert, P., Stratmann, F., Wiedensohler, A., Apituley, A., Shaw, R.A., Manninen, H.E., and Kulmala, M., 2010. Observations of turbulence-induced new particle formation in the residual layer, Atm. Chem. Phys., 10, 4319-4330.

Wiedensohler, A., Cheng, Y.F., Nowak, A., Wehner, B., Achtert, P., Berghof, M., Birmili, W., Wu, Z.J., Hu, M., Zhu, T., Takegawa, N., Kita, K., Kondo, Y., Lou, S.R., Hofzumahaus, A., Holland, F., Wahner, A., Gunthe, S.S., Rose, D., Su, H., and Pöschl, U., 2009. Rapid aerosol particle growth and increase of cloud condensation nucleus activity by secondary aerosol formation and condensation: A case study for regional air pollution in northeastern China, J. Geophys. Res., 114, D00G08, doi:10.1029/2008JD010884.

Yu, H., Liu, S.C., and Dickinson, R.E., 2002. Radiative effect of aerosols on the evolution of the atmospheric boundary layer, J. Geophys. Res., 107, D12, 4142, 10.1029/2001JD000754.

\section{ACKNOWLEDGEMENTS}

This work is funded by the German Research Foundation (DFG) under the number LA 2907/5-1. 